\title{
The relationship between spiritual intelligence and personality traits among Jordanian university students
}

This article was published in the following Dove Press journal:

Psychology Research and Behavior Management

18 March 2015

Number of times this article has been viewed

\author{
Ahmad M Mahasneh' \\ Nizar A Shammout' \\ Ziad M Alkhazaleh' \\ Ahmed F Al-Alwan' \\ Jawhara D Abu-Eita² \\ 'Department of Educational \\ Psychology, Faculty of Education \\ Sciences, Hashemite University, Zarqa, \\ Jordan; ${ }^{2}$ Department of Curricula, \\ Princess Alia College, Al-Balaq'a \\ Applied University, Amman, Jordan
}

\begin{abstract}
This study was aimed at identifying the level of spiritual intelligence and its correlation with personality traits among a group of Jordanian undergraduate students. A purposive sample of 716 male and female students was chosen from different faculties at the Hashemite University. Two questionnaires on spiritual intelligence and personality traits were distributed to members of the sample during the academic year 2013-2014. Results illustrated a medium level of spiritual intelligence in students, and indicated a positive and statistically significant relationship between spiritual intelligence dimensions (critical existential thinking, personal meaning production, transcendental awareness, and conscious state expansion) and personality traits (neuroticism, extraversion, openness to experience, agreeableness, and conscientiousness), but no significant correlation between personal meaning production and transcendental awareness dimensions and neuroticism personality traits. Finally, regression analysis results indicate that critical existential thinking is the first predictor dimension of spiritual intelligence in terms of neuroticism, extraversion, openness to experience, agreeableness, and conscientiousness. In the light of the results of this study, many recommendations were written by the researchers.
\end{abstract}

Keywords: Spiritual intelligence, personality traits, Jordanian University students

\section{Introduction}

The concept of intelligence emerged within the frame of ancient philosophy and has remained a topic of consistent interest to philosophers and writers throughout the ages to the present day. Recent decades, however, have witnessed an extension of this frame of reference to encompass contemporary research studies within the sciences of biology and physiology, particularly anorexia and bulimia nervosa physiology, heredity, and ultimately the field of the humanities.

The term and concept of spiritual intelligence emerged as a result of integrating intelligence with spirituality. ${ }^{1-5}$ While accepting the similarity and integration between religion and spirituality, there is also agreement as to their dissimilarity and distinction, religion focusing on the sacred whereas spirituality refers to the experiential elements of meaning, eminence, and excellence. ${ }^{6}$

Researchers regard spiritual intelligence as the most significant type of intelligence because of its ability to influence change in people, societies, and cultures. Thus, improving spiritual intelligence helps individuals toward adopting a positive outlook and in achieving inner peace. This modification in attitude improves self-motivation and control as well as helping to reduce the high stress levels commonly induced by

the hectic pace of modern life. ${ }^{7}$
Correspondence: Ahmad M Mahasneh Department of Educational Psychology, Faculty of Education Sciences, Hashemite University, Zarqa, Jordan

Email dahmadmahasneh1975@yahoo.com 
Mayer states that individuals attain spiritual awareness when the following are achieved: 1) being attuned to the holistic harmony of the world and surpassing self-limitation; 2) being aware of higher planes and states of spiritual thought and contemplation; 3 ) being conscious of the spiritual dimension of daily activities, events, and relationships; 4) building awareness, which means considering daily problems in the context of ultimate life parameters; and 5) desiring to improve or elevate the self, consequently practicing forgiveness, expressing appreciation and gratitude, and practicing humility and empathy. ${ }^{8}$

Emmons defines spiritual intelligence as the adaptive use of spiritual data to facilitate daily problem solving. ${ }^{1}$ Zohar and Marshal identify spiritual intelligence as a third type of intelligence that expands the construct of behavior. It is also the intelligence by whose standards our work and comprehensive path of life are evaluated in comparison with others. It is the base we need in order for our intellectual and emotional intelligence to work effectively. ${ }^{5}$ King defines it as the group of intellectual/mental capabilities that are based upon adaptation, nonmaterialistic principle, and far-fromreality aspects. ${ }^{9}$ Vaughan defines spiritual intelligence as interest in the individual's inner mental life, mood, and relation to the existence of life, thus implying the ability for deep understanding of questions related to existence as well as the consideration of various levels of emotion. ${ }^{4}$ Nasel defines it as the ability to distinguish, search for meaning, and solve spiritual issues, ${ }^{10}$ whereas Amram and Dryer see it as the ability to apply and use the spiritual features and capabilities which increase our life effectiveness and mental welfare. On the other hand, ${ }^{11}$ Wigglesworth sees it as behaving wisely and mercifully while maintaining both inner peace and outward calm regardless of the prevailing circumstances. ${ }^{12}$

Tekkeveettil suggests that those individuals with spiritual intelligence awareness reveal the following features and indications: flexibility (the individual's self-flexibility and ability to see the world realistically as a place of diversity and variety; also refers to the person's ability to interact, understand, and adapt to developments and innovation), selfawareness (examination of the inner self helps to comprehend one's true identity), the ability to face and learn from failure and fears, the ability to examine the relationships between different things and think collectively, and the ability to work. ${ }^{13}$

MacHovec sees that spiritual intelligence is a distinguished pattern of intelligence that surpasses variances in time, culture, and religion, and is an extension of Gardner's theory of multiple intelligences. Although spiritual intelligence differs from traditional intelligence, they share common features: they increase with age, reflect the individual's mental performance pattern, and consist of a group of interdependent abilities. ${ }^{14}$ In addition, spiritual intelligence is recognized as being the representative of intelligence, which means that it refers to the integration of all other types of intelligence. ${ }^{2}$

Emmons states that spiritual intelligence comprises a number of features or capabilities that vary from one person to another: the ability for excellence and eminence; the ability to access deep spiritual states of reflection, such as meditation and subjugation of self; the ability to use spiritual capacities and resources for solving daily problems; the ability to invest in the daily events, activities, and relations with others, in addition to behaving in a dignified manner in all things and toward all people; and the ability to behave with humanity and modesty, showing lenience, forgiveness, and gratitude, and expressing sympathy and humility. ${ }^{1,2}$ Noble delineated the innate human capacity for spiritual intelligence as two types of ability: the conscious realization of the materialistic reality which exists within a larger multidimensional domain, and seeking the achievement of psychological well-being. ${ }^{3}$

King identified the components of spiritual intelligence as the following: Critical existential thinking, or deducing and creating meaning based upon deep understanding of existence-related questions and the ability to use differing levels of emotion to facilitate problem solving; the achievement of personal or self-meaning through combining or integrating mental and physical experiences with personal or self-meaning, ${ }^{5,9}$ creating mental models of spiritual facts and formulating meaning from the data, ${ }^{8}$ and the ability to master and create life purpose, ${ }^{15}$ transcendental awareness, or the ability to understand and correlate one's relationship with all creatures in existence and the ability to coordinate different views ${ }^{4}$ to reach a deep understanding of interactions and interchanging relations between the self and others; ${ }^{9}$ and expansion of the state of consciousness, or the ability to remain focused, be stimulated and motivated by goals, think analytically, forgive and tolerate, accept contradictory or abnormal experiences, and achieve pure realization, deep insight, increasing empathy, better concentration, and greater understanding. ${ }^{16-18}$

Wilber mentions that spiritual intelligence develops and increases among individuals in three stages: the beginning stage, in which attention is focused on the self through moving toward God with supplication to Him, with prayer and thanks for His compassion, the gifts of serenity and peace, security, and assurance in times of personal adversity; conventional levels, which refer to harmony and cohesion with 
religion, an extension of self-interest to interest in others; and postconventional levels, or transference from the state of simple commitment to spiritual and religious consciousness to a broader inclusiveness of self-awareness, as well as understanding the different ways and means of reaching realization and coming to terms with reality. ${ }^{19}$

Personality is a set of psychological traits and mechanism within the individual which is organized, relatively endured, and influences the individual's adaptation to the environment. ${ }^{20}$ It consists of dynamic organization traits that determine how a person adjusts to the environment. ${ }^{21}$ Among the best developed models concerning personality traits is the Big Five model..$^{22,23}$ This model consists of five personality factors: neuroticism, extraversion, openness to experience, agreeableness, and conscientiousness. This model of personality can be used to describe the most salient aspects of personality. It combines people's emotions, attitude, and behavior, and was defined as a consistent pattern of thought, feelings, or actions that distinguish people from one another. ${ }^{24}$

Neuroticism has an inherent negative denotation. Goldberg found that neurotic people respond more poorly to environmental stress and are more likely to interpret ordinary situations as threatening and minor frustrations as hopelessly difficult. ${ }^{24}$ Individuals who are high in neuroticism may show more emotional reactions whenever confronted with stressful situations. ${ }^{25}$ Moreover, they seem to use avoiding and distracting coping strategies, such as denying, wishful thinking, and self-criticism rather than more approaching strategies. ${ }^{26-28}$

Extraversion refers to social adaptability, though the popularity of this term seems to be waning. ${ }^{29}$ Extraversion is the act, state, or habit of being predominantly concerned with and obtaining gratification from outside the self, defined as a trait characterized by a keen interest in other people and external events, and venturing forth with confidence into the unknown. ${ }^{30}$

Openness to experience refers to how willing people are to make adjustments in notions and activities in accordance with new ideas or situations. ${ }^{31,32}$ It includes traits like having wide interests, being imaginative and insightful, attentiveness to inner feelings, preference for variety, and intellectual curiosity. ${ }^{33}$

People with conscientiousness personalities are organized, plan ahead, and exhibit impulse control, though this should not be confused with the problems of impulse control found in neuroticism. People exhibiting neurotic impulsiveness find it difficult to resist temptation or delay gratification, while individuals have low conscientiousness are unable to motivate themselves to perform a task that they would like to accomplish. ${ }^{33}$

Agreeableness measures how compatible people are with other people, or how able they are to get along with others. It is a tendency to be pleasant and accommodating in social situations reflecting individual differences in concern for cooperation and social harmony. ${ }^{34}$ Agreeable traits include empathy, consideration, friendliness, generosity, and helpfulness, as well as an optimistic view of human nature. Agreeable persons tend to believe that most people are honest, decent, and trustworthy, and are less likely to suffer from social rejection.

\section{Previous studies}

In their study, Beshlideh et al conducted research with 270 male students at Shahid Chamran University at Ahvaz, examining the relationship between personality traits and spiritual intelligence. Analytical results showed statistically significant correlations between extraversion, agreeableness, and conscientiousness and critical existential thinking, personal meaning, transcendent awareness, and conscious-state spiritual intelligence, but showed no correlation between neurosis and openness personality traits and spiritual intelligence subscales..$^{35}$

Amrai et al conducted a study with 205 students at the University of Tehran to examine the relationship between personality traits and spiritual intelligence. The study results showed a positive relationship between the three personality traits of conscientiousness, agreeableness, and extroversion and spiritual intelligence, but a negative relationship between neuroticism and spiritual intelligence, while also showing no correlation between openness and spiritual intelligence. ${ }^{36}$

Sood et al conducted a study with 120 students at the Jammu and Indira Gandhi National Open University examining the relationship between personality traits, spiritual intelligence, and well-being. Results showed a positive relationship between self-meaning generation and agreeableness and neuroticism, and a significant relationship between transcendental awareness and openness. ${ }^{37}$

Farsani et al conducted a study with 121 physical education managers in Isfahan province, examining the relationship between spiritual intelligence and personality traits. The study results showed a positive significant correlation between spiritual intelligence (critical thinking, creating personal meaning, transcendental awareness, and expanding awareness) and personality traits of extraversion, agreeableness, conscientiousness, and openness to experience. Results 
also showed a negative and significant correlation between spiritual intelligence subscales and the neuroticism personality trait. ${ }^{38}$

\section{The current study}

It should be noted that few studies have been undertaken in Jordan or indeed in the Arab world related to the topic of spiritual intelligence. The present study was aimed at exploring the level of spiritual intelligence among Hashemite University students, and examining further the link between spiritual intelligence and personality traits. In order to achieve the objective of the present study, the following questions were generated: What is the level of spiritual intelligence among sample of undergraduate students at Hashemite University in Jordan? Is there significant correlation between spiritual intelligence and personality traits?

\section{Methodology \\ Study sample and population}

The present study adopted a descriptive research design approach. The study population consisted of all undergraduate students at the Hashemite University in Jordan $(\mathrm{N}=26,530)$ in the second semester of the academic year 2013-2014. Participants included 716 male and female students from different departments, different academic years, and all faculties, their selection based on purposive sample technique from the overall population. Six courses were chosen from the college of arts and sciences. Table 1 illustrates demographic characteristics of the study participants.

\section{Instruments}

Research instruments included two scales: the Spiritual Intelligence Questionnaire and the Personality Traits Questionnaire. The Spiritual Intelligence Questionnaire was

Table I Demographic characteristics of the study participants

\begin{tabular}{ll}
\hline Variable & N (\%) \\
\hline Sex & \\
Male & $304(42)$ \\
$\quad$ Female & $412(58)$ \\
Faculty & \\
Sciences & $331(46)$ \\
Humanities & $385(54)$ \\
Academic year & \\
First & $181(25)$ \\
Second & $173(24)$ \\
Third & $188(26)$ \\
Fourth & $174(24)$ \\
Total & $716(100)$ \\
\hline
\end{tabular}

developed by King and included 24 items for each of the four spiritual intelligence constructs: critical existential thinking (7 items), personal meaning production (5 items), transcendental awareness ( 7 items), and conscious state expansion (5 items). The items are rated on a five-point scale, ranging from the response (0) not at all true of me to (4) completely true of me. Higher scores represent higher levels of spiritual intelligence. $^{9}$

King reported coefficient Cronbach's alpha for the subscale $0.78,0.78,0.87$, and 0.91 , respectively for critical existential thinking, personal meaning production, transcendental awareness, and conscious state expansion. ${ }^{9}$ El-Rabeea adapted and validated an Arabic version of the King ${ }^{9}$ spiritual intelligence questionnaire for Yarmouk University students in Jordan. Cronbach's alpha was calculated at 0.72, 0.78, 0.72 , and 0.72 , respectively for critical existential thinking, personal meaning production, transcendental awareness, and conscious state expansion. ${ }^{39}$ In the current study, the reliability coefficient calculated using Cronbach's alpha was found to be $0.73,0.81,0.68$, and 0.83 , respectively for critical existential thinking, personal meaning production, transcendental awareness, and conscious state expansion.

The Personality Traits Questionnaire was developed by McCrae and Costa to measure the five personality domains: neuroticism, extraversion, openness to experience, agreeableness, and conscientiousness. The instrument consisted of 60 items, 12 items for each of the five domains. The instrument includes self-descriptive responses by the participants using a 1 (strongly disagree) to 5 (strongly agree) Likert-type scale. The internal consistency of the instruments was high (0.92, 0.89, 0.87, 0.86, 0.90, respectively) for neuroticism, extraversion, openness to experience, agreeableness, and conscientiousness. ${ }^{40}$ In the current study, the reliability coefficient calculated using Cronbach's alpha was found to be $0.67,0.64,0.63,0.65$, and 0.67 , respectively for neuroticism, extraversion, openness to experience, agreeableness, and conscientiousness.

\section{Data collection and analysis}

Data for the current study were collected for the spiritual intelligence scale and personality traits scale. The questionnaire was distributed by the researchers during March and April during the academic year of 2013-2014. The researchers selected six courses for university optional requirements during class sessions, explained the purpose and instruction of the study, assured confidentiality of results, and handed the scales to students. At the end of class sessions, scales were collected by researchers. Seven hundred sixteen scales 
were distributed at class sessions. Of these, 34 were unusable, resulting in a return rate of $95 \%$.

The alpha level was set at 0.05 a priori. Procedures for the statistical analysis are discussed by research questions. Research question one was to determine the level of spiritual intelligence among undergraduate students at Hashemite University in Jordan. Descriptive statistics were used to answer these questions by computing means and standard deviations for the four dimensions of students' spiritual intelligence. Research question two was to investigate the relationship between spiritual intelligence and personality traits. Person correlation was used to answer this question. The SPSS statistical package version 17 was employed to carry out these analyses.

\section{Results}

The first objective of the present study was to determine the level of spiritual intelligence among students at the Hashemite University. To achieve this objective, illustrative statistics including means and standard deviation were used and levels of spiritual intelligence interpreted as follows: below 3, low; 3-4, medium; above 4, high. ${ }^{41}$ Table 2 shows the mean for overall personal meaning production as 3.90 , critical existential thinking as 3.48, transcendental awareness as 3.41, and conscious state expansion as 3.39 , indicating a medium level of spiritual intelligence skills. The mean for neuroticism was 36.04, extraversion 42.31, openness to experience 39.63 , agreeableness 42.74, and conscientiousness 43.44 .

The second objective of this study was to investigate the relationship between spiritual intelligence and personality traits. The correlation matrix is presented in Table 3. There is a positive and statistically significant relationship at the level $(P=0.01)$ between spiritual intelligence dimensions (critical existential thinking, personal meaning production,

Table 2 Mean (standard deviation) of spiritual intelligence and personality traits

\begin{tabular}{ll}
\hline Variable & Mean (SD) \\
\hline Spiritual intelligence & \\
Critical existential thinking & $3.48(0.73)$ \\
Personal meaning production & $3.90(0.82)$ \\
Transcendental awareness & $3.41(0.66)$ \\
Conscious state expansion & $3.39(0.91)$ \\
Personality traits & \\
Neuroticism & $36.04(5.54)$ \\
Extraversion & $42.31(5.28)$ \\
Openness to experience & $39.63(4.99)$ \\
Agreeableness & $42.74(5.68)$ \\
Conscientiousness & $43.44(5.85)$ \\
\hline
\end{tabular}

Abbreviation: SD, standard deviation. transcendental awareness, and conscious state expansion) and personality traits (neuroticism, extraversion, openness to experience, agreeableness, and conscientiousness). Results also indicated no significant correlation between personal meaning production and transcendental awareness dimensions and neuroticism personality traits.

The predictive capability of personality traits for spiritual intelligence was determined using regression analysis of the spiritual intelligence dimensions, presented in Table 4. The results show that with critical existential thinking as a dependent variable, the global model was significant $\left(R^{2}=0.120, F=19.373, R=0.346, P<0.05\right)$, with the five variables (neuroticism, extraversion, openness to experience, agreeableness, and conscientiousness) accounting for $12 \%$ variance in critical existential thinking. With personal meaning production as a dependent variable, the global model was significant $\left(R^{2}=0.107, F=17.060, R=0.327, P<0.05\right)$, with the five variables (neuroticism, extraversion, openness to experience, agreeableness and conscientiousness) accounting for $10.7 \%$ of the variance of personal meaning production. With transcendental awareness as a dependent variable, the global model was significant $\left(R^{2}=0.057\right.$, $F=8.521, R=0.238, P<0.05$ ), with the five variables (neuroticism, extraversion, openness to experience, agreeableness, and conscientiousness) accounting for $5.7 \%$ variance of transcendental awareness. For conscious state expansion, with personal meaning production as a dependent variable, the global model was significant $\left(R^{2}=0.093, F=14.593\right.$, $R=0.305, P<0.05$ ), with the five variables (neuroticism, extraversion, openness to experience, agreeableness, and conscientiousness) accounting for $9.3 \%$ variance of conscious state expansion.

\section{Discussion}

Mental or intellectual capacities are not the sole variables to affect individual performance and the scores subsequently achieved in intelligence ratings, but may also be influenced by nonmental personal or mood variables.

Given a broad definition of personality as a dynamic and organized set of characteristics, intelligence might well be described as a personality trait and was indeed considered as such by some early theorists, including Cattell and Guilford in the 1950s. This view is, however, refuted by most later theorists, who do not consider intelligence as an integral part of personality, but rather contend that intelligence is unrelated to personality or concur with ${ }^{42}$ Chamorro-Premuzic and Furnham that intelligence and personality are related, but nonetheless categorically distinct. ${ }^{42-43}$ 
Table 3 Correlation matrix of spiritual intelligence and personality traits

\begin{tabular}{lllll}
\hline Variable & $\begin{array}{l}\text { Critical existential } \\
\text { thinking }\end{array}$ & $\begin{array}{l}\text { Personal meaning } \\
\text { production }\end{array}$ & $\begin{array}{l}\text { Transcendental } \\
\text { awareness }\end{array}$ & $\begin{array}{l}\text { Conscious state } \\
\text { expansion }\end{array}$ \\
\hline Neuroticism & $0.20^{*}$ & -0.06 & 0.03 & $0.16^{*}$ \\
Extraversion & $0.13^{*}$ & $0.12^{*}$ & $0.14^{*}$ & $0.19^{*}$ \\
Openness to experience & $0.17^{*}$ & $0.23^{*}$ & $0.13^{*}$ & $0.21^{*}$ \\
Agreeableness & $0.23^{*}$ & $0.19^{*}$ & $0.13^{*}$ & $0.17^{*}$ \\
Conscientiousness & $0.26^{*}$ & $0.21^{*}$ & $0.23^{*}$ & $0.29^{*}$ \\
\hline
\end{tabular}

Note: *Significant at a level of $P<0.01$.

This study aimed to identify the level of spiritual intelligence among the Hashemite University student sample, and also to investigate the correlation between spiritual intelligence and personality traits. Analysis of results of participants' responses to the first objective of this study, the spiritual intelligence questionnaire, indicated a medium level of spiritual intelligence. This result could be explained in light of the innovativeness of the spiritual intelligence concept and its subsequent lack of recognition by the university as a bona fide field of study. Increased attention and focus on this important area through academic courses and training programs would not only improve the effectiveness of spiritual intelligence among students, but also elevate the prestige and distinction of the university.

The second aim of this study was to investigate the correlation between spiritual intelligence and personality traits among the Jordanian student sample. Results revealed a positive and statistically significant relation between spiritual intelligence dimensions (critical existential thinking, personal meaning production, transcendental awareness, and conscious state expansion) and personality traits (neuroticism, extraversion, openness to experience, agreeableness, and conscientiousness), but showed no significant correlation between personal meaning production and transcendental awareness dimensions and the neuroticism personality trait.

The correlation between neuroticism and spiritual intelligence can be interpreted as the theoretical concept of spiritual intelligence, since spiritual intelligence questions meaning or values and is based on social or spiritual life. Thus, spiritual intelligence appears to be to be a way of administering the human mind effectively, so the person enjoying a high level of spiritual intelligence has control over his reactions and responses, and a high level power of thought. Clearly, these characteristics are diametrically opposite to those engendered by neuroticism, since neurotics are always anxious, worried, stressed, easily angered, and unable to control their reactions and responses.

Regarding the positive correlation between spiritual intelligence and extraversion, this result can be illustrated

Table 4 Results of regression analysis predicting personality traits

\begin{tabular}{|c|c|c|c|c|c|c|}
\hline Spiritual intelligence & Personality traits & $\boldsymbol{R}$ & $R^{2}$ & $\boldsymbol{F}$ & $\beta$ & $\mathbf{T}$ \\
\hline \multirow[t]{5}{*}{ Critical existential thinking } & Neuroticism & 0.346 & 0.120 & 19.373 & 0.052 & 1.282 \\
\hline & Extraversion & & & & 0.218 & 4.500 \\
\hline & Openness to experience & & & & -0.069 & -1.516 \\
\hline & Agreeableness & & & & 0.091 & 2.228 \\
\hline & Conscientiousness & & & & 0.122 & 2.601 \\
\hline \multirow[t]{5}{*}{ Personal meaning production } & Neuroticism & 0.327 & 0.107 & 17.060 & -0.204 & -5.048 \\
\hline & Extraversion & & & & -0.032 & -0.666 \\
\hline & Openness to experience & & & & 0.172 & 3.773 \\
\hline & Agreeableness & & & & 0.147 & 3.585 \\
\hline & Conscientiousness & & & & 0.150 & 3.183 \\
\hline \multirow[t]{5}{*}{ Transcendental awareness } & Neuroticism & 0.238 & 0.057 & 8.521 & -0.075 & -1.802 \\
\hline & Extraversion & & & & 0.017 & 0.340 \\
\hline & Openness to experience & & & & 0.004 & 0.092 \\
\hline & Agreeableness & & & & 0.060 & 1.409 \\
\hline & Conscientiousness & & & & 0.215 & 4.447 \\
\hline \multirow[t]{5}{*}{ Conscious state expansion } & Neuroticism & 0.305 & 0.093 & 14.593 & 0.052 & 1.287 \\
\hline & Extraversion & & & & -0.029 & -0.581 \\
\hline & Openness to experience & & & & 0.062 & 1.355 \\
\hline & Agreeableness & & & & 0.052 & 1.246 \\
\hline & Conscientiousness & & & & 0.234 & 4.921 \\
\hline
\end{tabular}


based upon the logical link between the concept of spiritual intelligence and extraversion characteristics, people who are cheerful, friendly, and warm in their social relationships; in addition, they are characterized by healthy vigor, enjoy all types of physical activity, and feel positive emotions such as happiness, love, excitement, and enjoyment.

Sternberg sees the production of personal meaning as the ability to build character and identify the goal of all physical and mental experiences, including the ability to create a goal and significance for life, as well as the contemplation of existence. It is noted that character is sometimes described as an element of spirituality, indicating that spiritual intelligence implies contemplation of the significance of personal events and conditions in order to generate a goal and meaning for all life experiences. ${ }^{44}$

Our findings are consistent with those of Amrai et al, Beshlideh et al, Farsani et al, and Sood et al, illustrating a positive relationship between spiritual intelligence and personality traits. ${ }^{35-38}$

Emmons expresses the view that there appears little doubt as to the relationship between personality processes and intelligence, asserting the possibility that personality characteristics or components are linked to individual variances in establishing and expressing spiritual intelligence. ${ }^{1}$ Wolman and MacHovec concur the latter elucidating further by stating some personality components to be more concordant with spiritual intelligence characteristics than others. ${ }^{14,45}$ Any attempt to examine, investigate, or correlate various personality theories inevitably recognizes the comprehensive range of characteristics encompassed in McCrae and Costa's Big Five personality theory, while noting that these researchers join a consensus of opinions finding the characteristics most commonly used to express spiritual intelligence. These attributes of emotional stability, agreeableness, and openness are concordant with the stable, kind, responsible, open-minded, and creative natures associated with a high level of spiritual intelligence development. ${ }^{46}$

Piedmont, however, presents an alternative view, positing that spirituality may represent a separate attribute of personality. ${ }^{47}$ This is supported and expanded upon by MacHovec contending that spiritual intelligence may be regarded as a personality attribute which, just as with any other personality characteristic, differs among individuals in intensity of expression. Its particularity, however, is attributed to life experience, which by its very nature is distinctly individual, idiosyncratic, and subjective, described as an all-encompassing transcendental quality revealed in a perceptive and effective manner, contributory and conducive to creativity, development, and extension of self. MacHovec describes the realization of this kind of subjective experience linked with spiritual intelligence as a feeling of enlightenment, wonder, inspiration, or heightened awareness. ${ }^{14}$ This perspective may be viewed as an extension of James, and later, of Allport's hypotheses that religiousness and spirituality ought to be considered as a facet of the individual's personality structure, providing a complete instruction manual for life, a constructive awareness which puts the individual, his emotions, behavior, hopes, and fears in clear perspective and context. ${ }^{48-50}$ Yet the concept of spiritual intelligence as a definite factor contributing to personality structure has been neither adequately studied nor developed, even theoretically. Following Piedmont's line of thought, spiritual intelligence may present a combination of personality factors (interest in, expression of, and access to spiritual information) and intelligence-related information processing (aptness and skills for effective processing of this type of information). ${ }^{47}$ In fact, the very concept can be expanded to include additional, equally substantial individual strengths and capabilities such as the natural capacity for parenting, tending and caring for those in need, or artistic expression. It may be claimed that such intrinsic predispositions, by their very presence, are dedicated conduits for the expression of spiritual intelligence and may be fostered, nurtured, and reinforced by the development of spiritual intelligence..$^{51}$

\section{Recommendations}

The faculty should take the lead in this important field with how spiritual intelligence competencies might be developed through such methods as training, coaching, and therapy. From a theoretical standpoint, we suggest that future researches work on adapting/designing new instruments in spiritual intelligence through exploratory and confirmatory factor analysis. Future research should examine the relationship between spiritual intelligence and other variables such as emotional intelligence, parenting styles, academic achievement, and motivation.

\section{Limitations}

A limitation of the current study is statistical significance and adequate effect in the relationship between spiritual intelligence and personality traits. It is important to note that this study used the correlation method, and hence no clear cause and effect conclusions can be drawn from the results. Future studies might consider using an experimental design. Another limitation of this study being part of class assignment is that it was not possible timewise for participants to be recruited 
for another sampling method. Furthermore, the structure of the current study was such that reliability analysis could not be performed because only total scores for each questionnaire were entered into SPSS.

\section{Conclusion}

The main purpose of the current study was to assess the level of spiritual intelligence among undergraduate students at Hashemite University in Jordan and to find the association between spiritual intelligence and personality traits. The findings of the current study suggest that the level of spiritual intelligence is medium in students at the Hashemite University in Jordan. The most important finding that can be drawn from this study was that a positive and statistically significant relationship exists between spiritual intelligence dimensions (critical existential thinking, personal meaning production, transcendental awareness, and conscious state expansion) and personality traits (neuroticism, extraversion, openness to experience, agreeableness, and conscientiousness), but no significant correlation between personal meaning production and transcendental awareness dimensions and neuroticism personality traits was found. Regression analysis results indicate that critical existential thinking is the first predictor of spiritual intelligence in terms of neuroticism, extraversion, openness to experience, agreeableness, and conscientiousness.

\section{Disclosure}

The authors report no conflicts of interest in this work.

\section{References}

1. Emmons R. Is spirituality an intelligence? Motivation, cognition and the psychology of the ultimate concern. Int J Psychol Relig. 2000;10(1): 3-26.

2. Emmons R. Spirituality and intelligence: Problems and prospects. Int J Psychol Relig. 2000;10(1):57-64.

3. Noble K. Spiritual intelligence: A new frame of mind. Advanced Development. 2000;9:1-29.

4. Vaughan F. What is spiritual intelligence? J Humanist Psychol. 2002;42(2):16-33.

5. Zohar D, Marshall I. SQ: Connecting with Our Spiritual Intelligence. New York: Bloomsbury; 2000.

6. Worthington E. Religion and spirituality. Psychotherapy. 2001;38(4): 473-478.

7. Buzan T. The power of spiritual intelligence: 10 ways to tap into your spiritual genius. New York: Harper Collins Publishers LTD; 2001.

8. Mayer J. Spiritual intelligence or spiritual consciousness? Int J Psychol Relig. 2000;10(1):47-56.

9. King D. Rethinking claims of spiritual intelligence: A definition, model, and measure [master's thesis]. Peterborough, ON, Canada: Trent University; 2008.

10. Nasel D. Spiritual orientation in relation to spiritual intelligence: A new consideration of traditional Christianity and New Age/individualistic spirituality [doctoral dissertation]. Adelaide, Australia: University of South Australia; 2004.
11. Amram Y, Dryer C. The Integrated Spiritual Intelligence Scale (ISIS): development and preliminary validation. Paper presented at the 116th Annual Conference of the American Psychological Association, Boston, MA, August 2008. Available at: http://www.yosiamram.net/ papers. Accessed November 26, 2014.

12. Wigglesworth C. Spiritual intelligence: what is it? how can we measure it? why would business care [webpage on the Internet]? Available at: http://www.kpokorny.com/content/user_files/spiritual_intelligencewhat_is_it.pdf. Accessed November 26, 2014.

13. Tekkeveettil CP. IQ and EQ give way to spiritual intelligence, the ultimate intelligence that can add value and meaning to your life [webpage on the Internet]. http://lifepositive.com/mind/evolution/ iqgenius/intelligence.asp.

14. MacHovec FJ. Spiritual intelligence, behavioral sciences, and the humanities. Lewiston, NY: Edwin Mellen Press; 2002.

15. Wink P, Dillon M. Spiritual development across the adult life course: findings from a longitudinal study. J Adult Dev. 2002;9(1):79-94.

16. Louchakova O. On advantages of the clear mind: Spiritual practices in the training of a phenomenological researcher. Humanistic Psychol. 2005;33(2):87-112.

17. Valentine ER, Sweet PLG. Meditation and attention: A comparison of the effects of concentrative and mindfulness meditation on sustained attention. Ment Health Relig Cult. 1999;2(1):59-70.

18. Vaitl D, Birbaumer N, Gruzelier J, et al. Psychobiology of altered states of consciousness. Psychol Bull. 2005;131(1):98-127.

19. Wilber K. Integral Psychology: Consciousness, Spirit, Psychology, Therapy. Boston: Shambhala; 2000.

20. Pervin LA, John OP. Personality: Theory and Research. 7th ed. New York: John Wiley and Sons; 1997.

21. Allport GW. Pattern and Growth in Personality. New York: Holt, Rinehart and Winston; 1961.

22. Digman JM. Personality structure: Emergence of the five-factor model. Annu Rev Psychol. 1990;41:417-440.

23. McCrae RR, Costa PT. The stability of personality: Observation and evaluations. Curr Dir Psychol Sci. 1994;3:173-175.

24. Goldberg LR. An alternative "description of personality": the big-five factor structure. J Pers Soc Psychol. 1990;59(6):1216-1229.

25. Van Heck GL. Personality and physical health: Toward an ecological approach to health-related personality research. Eur J Pers Res. 1997;11:415-443.

26. Bolger N. Coping as a personality process: A prospective study. J Pers Soc Psychol. 1990;59(3):525-537.

27. Heppner PP, Cook SW, Wright DM, Johnson WC. Progress in resolving problems: A problem-focused style of coping. J Couns Psychol. 1995;42:279-293.

28. McCrae RR, Costa PT. Personality, coping, and coping effectiveness in an adult sample. J Personality. 1986;54:385-404.

29. Zuckerman M. Psychobiology of Personality. New York: Cambridge University Press; 1991.

30. Ewen RB. Personality: A Topical Approach: Theories, Research, Major Controversies, and Emerging Findings. Mahwah, NJ: Lawrence Erlbaum; 1998.

31. Goldberg LR. The structure of phenotypic personality traits. Am Psychol. 1993;48(1):26-34.

32. McCrae RR, John OP. An introduction to the five-factor model and its applications. J Pers. 1992;60(2):175-215.

33. Costa PT, McCrae RR. Four ways five factors are basic. Pers Indiv Differ. 1992;13(6):653-665.

34. Graziano WG, Eisenberg NH. Agreeableness: A dimension of personality. In: Hogan R, Johnson J, Briggs S, editors. Handbook of Personality Psychology. San Diego, CA: Academic Press; 1997:795-824.

35. Beshlideh K, Charkhabi M, Kalkhoran MAN, Marashi SA. Relationship between personality traits and spiritual intelligence in male students of Shahid Chamran University at Ahvaz. Int J Psychol. 2011;5(1):21-34.

36. Amrai K, Farahani A, Ebrahimi M, Bagherian V. Relationship between personality traits and spiritual intelligence among university students. Procedia Soc Behav Sci. 2011;15:609-612. 
37. Sood S, Bakhshi A, Gupta R. Relationship personality traits, spiritual intelligence and well being in university students. J Educ Pract. 2012;3(10):55-59.

38. Farsani ME, Arofzad S, Hosaini TA. The study of the relationship spiritual intelligence with personality traits among physical education managers in Isfahan province. Adv Appl Sci Res. 2013;4(4):140-144.

39. El-Rabeea F. Spiritual intelligence and its relationship to gender and achievement level of the students in the Faculty of Education at Yarmouk University in Jordan. Jordanian Journal of Educational Sciences 2013;9(4):353-364.

40. McCrae RR, Costa PT. A contemplated revision of the NEO Five-Factor Inventory. Pers Individ Dif. 2004;36(3):587-596.

41. Glass GV, Hopkins KD. Statistical Methods in Education and Psychology. 3rd ed. Boston: Allyn and Bacon; 1996.

42. Eysenck HJ, Eysenck SBG. Priručnik za Eysenckove skale ličnosti: EPS-odrasli [A manual for eysenck's personality scales: EPS-adults. In Croatian] Naklada Slap, Jastrebarsko; 1994.

43. Chamorro-Premuzic T, Furnham A. Personality and Intellectual Competence. Mahwah, New Jersey: Lawrence Erlbaum Associates; 2005.
44. Sternberg RJ. Successful Intelligence: How Practical and Creative Intelligence Determine Success in Life. New York: Plume; 1997.

45. Wolman RN. Thinking with Your Soul: Spiritual Intelligence and Why it Matters. 1st ed. New York: Harmony Books; 2001.

46. McCrae RR, Costa PT. Personality in Adulthood. New York: Guilford; 1990.

47. Piedmont RL. Does spirituality represent the sixth factor of personality? Spiritual transcendence and the five-factor model. J Pers. 1999;67(6):985-1013.

48. James W. The Varieties of Religious Experience: A Study in Human Nature. 2nd ed. London: Longmans, Green, and Co; 1905.

49. James W. The Varieties of Religious Experience: A Study in Human Nature. New York: Collier Books; 1961.

50. Allport GW. The individual and his religion. New York: Macmillan; 1961.

51. Sinetar M. Spiritual intelligence. What we can learn from the early awakening child Maryknoll, NY: Orbis Books; 2000.

\section{Publish your work in this journal}

Psychology Research and Behavior Management is an international, peerreviewed, open access journal focusing on the science of psychology and its application in behavior management to develop improved outcomes in the clinical, educational, sports and business arenas. Specific topics covered include: Neuroscience, memory \& decision making; Behavior

\section{Dovepress}

modification \& management; Clinical applications; Business \& sports performance management; Social and developmental studies; Animal studies. The manuscript management system is completely online and includes a quick and fair peer-review system. Visit http://www.dovepress. com/testimonials.php to read real quotes from published authors.

Submit your manuscript here: http://www.dovepress.com/psychology-research-and-behavior-management-journal 